ASLI QoL 2021

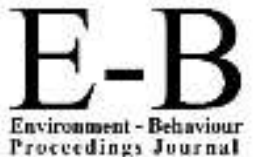

Proceeding, Juurnal

\section{AQoL2021Langkawisland}

https://www.amerabra.org; https://fspu.uitm.edu.my/cebs; https://www.emasemasresources.com/

$5^{\text {th }}$ ABRA International Conference on Quality of Life

Holiday Villa Langkawi, Langkawi Island, Malaysia, 15-16 Dec 2021

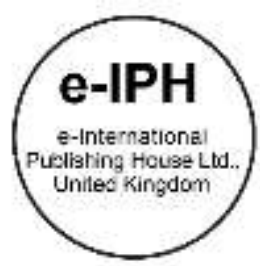

\title{
Structured Deep Breathing Exercises Education in Patient with Coronary Artery Bypass Graft
}

\author{
Noraini Hashim ${ }^{1}$, Norhaini Majid ${ }^{1}$, Norizan Masri ${ }^{1}$, Suryanto Suryanto ${ }^{2}$ \\ ${ }^{1}$ Centre for Nursing Studies, Faculty of Health Sciences, Universiti Teknologi MARA, Malaysia, \\ ${ }^{2}$ School of Nursing, Faculty of Medicine, Universitas Brawijaya, Indonesia
}

norainihashim1212@gmail.com, majidnorhaini@gmail.com, suryanto.s@ub.ac.id, nooreyzanmasri@ppukm.ukm.edu.my

Tel: +60196671709

\begin{abstract}
Pre-operative evaluation and patient preparation for cardiac surgery affect post-operative outcomes and progress. A standardized pre-operative education will ensure that adequate and correct information is delivered to the patients. The research aims to determine the effectiveness of structured deep breathing exercises education on oxygenation in patients with coronary artery bypass graft (CABG) surgery. The study used a quasi-experimental design. A total of 81 patients were recruited for this study. The $\mathrm{SpO}_{2}$ and $\mathrm{PaO} 2$ levels were measured using capillary saturation and Arterial Blood Gases (ABG). The results showed significant differences in $\mathrm{SpO}_{2}$ scores between control and intervention groups post-intervention.
\end{abstract}

Keywords: Pre-operative education; Cardiac surgery; deep breathing exercises

eISSN: 2398-4287C 2021. The Authors. Published for AMER ABRA cE-Bs by e-International Publishing House, Ltd., UK. This is an open access article under the CC BYNC ND license (http://creativecommons.org/licenses/by-nc-nd/4.0/). Peer-review under responsibility of AMER (Association of Malaysian Environment-Behaviour Researchers), ABRA (Association of Behavioural Researchers on Asians/Africans/Arabians) and cE-Bs (Centre for Environment-Behaviour Studies), Faculty of Architecture, Planning \& Surveying, Universiti Teknologi MARA, Malaysia.

DOI: https://doi.org/10.21834/ebpj.v6i18.3075

\subsection{Introduction}

Breathing is a normal physiological process that maintains the body's vital function. Breathing is a complex behaviour requiring the coordinated activity of several muscle groups both in the upper airway and in the chest wall. The normal breathing pattern gets affected in several ways; surgery is the most important. Surgery is an anxiety-provoking event and becomes more stressful when the internal organs are involved. An article on pre-operative prediction of post-operative complications revealed that stress and anxiety, directly and indirectly, decrease pulmonary function (Villa et al., 2020). The patients undergoing thoracic surgeries developed pulmonary dysfunction more frequently than the surgeries from other body parts.

Pre-operative evaluation and patient preparation for cardiac surgery affect post-operative outcomes and progress. The primary goal of a pre-surgical assessment is the evaluation of pre-operative risk. An in-depth assessment assists in minimizing surgical risk and potential morbidity and mortality. An evaluative screening identifies special needs that may require modification of the patient's course of treatment before, during, and after surgery.

\subsection{Literature Review}

Many measures have been employed to prevent pulmonary complications, such as administering broad-spectrum antibiotics, adequate pain management by opioids, early mobilization, chest physiotherapy and exercises. The simplest and easiest methods to prevent

eISSN: 2398-4287@ 2021. The Authors. Published for AMER ABRA cE-Bs by e-International Publishing House, Ltd., UK. This is an open access article under the CC BYNCND license (http://creativecommons.org/licenses/by-nc-nd/4.0/). Peer-review under responsibility of AMER (Association of Malaysian Environment-Behaviour Researchers), ABRA (Association of Behavioural Researchers on Asians/Africans/Arabians) and CE-Bs (Centre for Environment-Behaviour Studies), Faculty of Architecture, Planning \& Surveying, Universiti Teknologi MARA, Malaysia.

DOI: https://doi.org/10.21834/ebpj.v6i18.3075 
pulmonary complications are deep breathing exercises (Ünver et al., 2018). A study on respiratory muscle training with incentives spirometry proved that deep breathing and coughing exercises are the most frequently used techniques to promote optimum ventilation and gas exchange (Franklin \& Anjum, 2021). It loosens secretions and forces them to be expelled from the airway following CABG. They are usually instituted when the patient's condition is stable, especially during pre-operative. Yet, no study to date has investigated the effect of health education on deep breathing exercises in the public hospital's cardiothoracic units in Selangor. However, deep breathing exercises are encouraged the patient with CABG.

A nurse's attitude affects the amount of information given to the patient. Sometimes, nurses' work overload provides routine preoperative care but insufficient information regarding the surgery phase (Malley, 2015). Patients are left to find out about the surgery or anything they want to know through others. The factors that influence the amount of information given by nurses to patients are related to time availability, language barrier, the type of question that the patients asked the doctor's responsibility for providing information, tight operation schedules and expecting patients to clarify doubts themselves (Liu, \& Aungsuroch, (2018). A standardized pre-operative education will ensure that adequate and correct information is provided to the patients. There are limited studies on the effectiveness of structured deep breathing exercises on oxygenation in post-CABG surgery patients. Nurses are seen to deliver the information to the patient pre-operatively without referring to any teaching material. Therefore, this study aimed to develop and conduct a structured preoperative education intervention, especially in deep breathing exercises pre-operatively. The research objective is to determine the effectiveness of structured deep breathing exercises education on oxygenation in patients with coronary artery bypass graft (CABG) surgery.

\subsection{Methodology}

This research was conducted in one of the Cardiothoracic Units in a tertiary hospital situated at Selangor, Malaysia. The study is a quasiexperimental design. Non-equivalent control group before-after design, which involves two groups of subjects measured before and after the implementation of the intervention. In this study, there is a control group and an intervention group. The control group received routine deep breathing exercises by physiotherapy. In contrast, the intervention groups was received regular deep breathing exercises plus a booklet instruction of breathing exercises a day before the operation. Ethical approval was granted from the UiTM and Medical Research and Ethics Committee (NMRR-16-2670-33049(IIR).

The participants were recruited from the cardiothoracic clinic undergoing coronary artery bypass surgery (CABG). Purposive sampling methods are used in this study since the sampling frames are not available for many populations, and it is difficult to find suitable subjects for this study. As a component of this study design, participants are selected based on the inclusion and exclusion criteria of the groups. Participants are identified through computerized census data and recruited from the Cardio-Thoracic Unit. Before starting the study, every participant explained the purpose of the study through an information sheet by the researcher. Participants were informed that the participants are voluntary ad participants can withdraw from the study at any time. The study compared oxygenation levels between the intervention and control groups. The sample for this study was 38 participants in the control group and 43 participants in the intervention group.

Two main instruments used were a demographic information sheet, including socio-demographic and clinical data, to collect patients' primary data. The assessment forms to assess the patient's condition pre-operatively. The researchers delivered the structured preoperative education one day before the surgery and provided a booklet instruction about deep breathing exercises. There was an instructor's manual with detailed information on an illustration of the step of deep breathing exercises. The booklet contents included the aim of deep breathing exercise, the active cycle of breathing, part of active cycle of breathing exercise and illustration on deep breathing exercise. The pamphlet was explicitly designed by the researcher $s$ based on previous literature, medical and surgical book and personal experiences of ICU nursing. The final version was reviewed by a surgeon, a specialist in the Cardiothoracic Unit. Participant's family members were encouraged to get involved during pre-operative education intervention. In addition, the booklet was used as a resource that gave to the participant. The booklet acted as a guide for any further questions and concerns the participant may have. Besides, the demonstration of exercises such as deep breathing exercises aimed to enhance lung to expand.

After the routine pre-operative teaching and the structured pre-operative education intervention, both control and intervention groups $\mathrm{SpO} 2$ were monitored by a pulse oximeter attached at the finger. Then, a physician took ABG via arterial to measure the oxygenation level a day before operation in the ward. After the decision to operate, the ABG result of Pao2 level and pulse oximeter for SpO2 had been recorded at the participant laboratory result sheet for further investigation. Therefore, the researcher recorded the result as baseline data. In addition, the participant's $\mathrm{PaO} 2$ level was taken via arterial blood sample collected on post-op day 1(POD1) and post-op day 2 (POD2) via arterial line, which is attached to the participant after operation to compare differences of oxygenation level from day 1 to day 2 .

\subsection{Data Collection Procedure \\ Pre-operative Data Collection}

Participants had been recruited to participate in the study when they were admitted to the cardiothoracic unit for surgery. First, the researcher explained the purpose of the study. Then, when the participant agreed to participate, written consent was obtained. Then, participants were asked to complete the personal demographics information sheet. Finally, before the routine pre-operative teaching by the physiotherapist in the ward, the participants were tested on their oxygenation level ( $\mathrm{SpO} 2$ and PaO2) measurement via blood sample test. 


\section{The Groups and Deep Breathing Exercises}

The day before the operation, all respondents were received general information about post-operative routines by the physical therapist. All participants were received chest physical therapy once or twice daily. The treatment consisted of early mobilization, instruction in effective coughing techniques, daily active exercises of the shoulder and positioning from side to side. The respondents were taught deep breathing exercises without referring to any pamphlet. However, the participants in the intervention group were informed and practiced the deep breathing technique pre-operatively with a structured pamphlet by the researcher.

\section{The Study Group of Deep Breathing Exercises With Pamphlet}

The exercises were started approximately one hour after extubation. The participants had been encouraged to perform 30 deep breaths once per hour when awake (in the daytime) for the first two post-operative days. The exercises included three sets of 10 deep breathes with a $30-60$ second pause between each set. If needed, the participants were asked to cough during the pause to mobilize secretions. Participants of the intervention groups were received a structured chest physiotherapy program by the researcher:-

1. Started on the morning of the first post-operative day (POD1)

2. Twice a day in POD2

3. Once a day from third to the ten days

During any session, the participants were performed three to five deep breaths interspersed with periods of quiet breathing followed by two or three coughs and huffs (with wound support by a pillow or hands). This maneuver was carried out at least ten times over 15 minutes. In addition, participants were instructed to perform breathing and coughing independently every three hours.

\subsection{Findings}

\section{Socio-demographic Data}

There is no significant difference in the distribution in both the control and intervention groups in socio-demographic data. In addition, there were no statistically significant differences found between the gender, age, ethnic groups, education level, working status, history of hospitalization and surgery experience in both groups $(p>0.05)$. The results are shown in Table 1.

\begin{tabular}{|c|c|c|c|c|c|}
\hline \multirow{2}{*}{$\begin{array}{l}\text { Socio-demographic } \\
\text { Characteristic }\end{array}$} & & \multicolumn{4}{|l|}{ Group } \\
\hline & & $\begin{array}{l}\text { Control } \\
(\mathrm{n}=38) \\
(\mathrm{n}, \%)\end{array}$ & $\begin{array}{l}\text { Intervention } \\
(n=43) \\
(n, \%)\end{array}$ & $x_{3}^{2}$ & $p$ \\
\hline \multirow[t]{2}{*}{ Gender } & Male & $\begin{array}{l}22 \\
57.9\end{array}$ & $\begin{array}{c}28 \\
65.1\end{array}$ & 0.45 & 0.50 \\
\hline & Female & $\begin{array}{l}16 \\
42.1\end{array}$ & $\begin{array}{l}15 \\
34.9\end{array}$ & & \\
\hline \multirow[t]{3}{*}{ Age(Year) } & $18-39$ & $\begin{array}{l}11 \\
28.9\end{array}$ & $\begin{array}{l}13 \\
30.2\end{array}$ & 0.18 & 0.98 \\
\hline & $40-59$ & $\begin{array}{l}13 \\
34.2\end{array}$ & $\begin{array}{l}16 \\
37.2\end{array}$ & & \\
\hline & $>60$ & $\begin{array}{l}14 \\
36.9\end{array}$ & $\begin{array}{l}14 \\
32.6\end{array}$ & & \\
\hline \multirow[t]{4}{*}{ Ethnic group } & Malay & $\begin{array}{l}17 \\
44.7\end{array}$ & $\begin{array}{l}20 \\
46.5\end{array}$ & 0.40 & 0.94 \\
\hline & Chinese & $\begin{array}{l}15 \\
39.5\end{array}$ & $\begin{array}{l}17 \\
39.5\end{array}$ & & \\
\hline & India & $\begin{array}{l}2 \\
5.3\end{array}$ & $\begin{array}{l}3 \\
7.0\end{array}$ & & \\
\hline & Others & $\begin{array}{l}4 \\
10.5\end{array}$ & $\begin{array}{l}3 \\
7.0\end{array}$ & & \\
\hline \multirow[t]{3}{*}{ Education level } & $\begin{array}{l}\text { Less than primary } \\
\text { level or primary } \\
\text { level }\end{array}$ & $\begin{array}{l}10 \\
26.3\end{array}$ & $\begin{array}{l}8 \\
18.6\end{array}$ & 0.71 & 0.70 \\
\hline & Secondary level & $\begin{array}{l}22 \\
57.9\end{array}$ & $\begin{array}{l}27 \\
62.8\end{array}$ & & \\
\hline & $\begin{array}{l}\text { College } \\
\text { university }\end{array}$ & $\begin{array}{l}6 \\
15.8\end{array}$ & $\begin{array}{l}8 \\
18.6\end{array}$ & & \\
\hline Working status & Working & $\begin{array}{l}16 \\
42.1\end{array}$ & $\begin{array}{l}21 \\
48.8\end{array}$ & 0.37 & 0.54 \\
\hline
\end{tabular}




$\begin{array}{llllll} & \text { Not working } & 22 & 22 & & \\ & & 57.9 & 51.2 & & \\ \text { Prior hospitalization } & \text { Yes } & 31 & 41 & 0.08 \\ & & 81.6 & 95.3 & & \\ & \text { No } & 7 & 2 & 0.11 \\ \text { Prior to surgery } & \text { Yes } & 18.4 & 4.7 & & \\ & & 21 & 31 & & \\ & \text { No } & 55.3 & 72.1 & & \\ & & 44.7 & 27.9 & \end{array}$

Mann-Whitney U-test

${ }^{*} \mathrm{p}<0.05$ was statistically significant

\section{Comparison of $\mathrm{SpO} 2$ level between control and intervention groups}

Oxygen pulse oximeters are used to measure peripheral oxygen saturation $(\mathrm{SpO})$ for all respondents. The score was assessed as a baseline during pre-intervention and pre-operative. The median value result found in the control group was $99.0 \%(6.00)$, while the intervention group was $98.0 \%(4.00)$-no significant difference in SpO2 score between the two groups as a baseline $(Z=712, p=0.321)$. In post-intervention (pre-operative), there were significant differences found between the $S p O 2$ score $(Z=603.0), p=0.041)$. The result has shown median value was $98.0(5.00)$ in the control group compared to $99.0 \%$ (6.50) in the intervention group. On Post Operation Day 1(POD1), the result showed a statistically significant difference in SpO2 score in the control group, which is median value $96.00 \%$ (3.00) compared to intervention 5.50 in the intervention group with $(Z=585.0, p=00.27)$. On Post Operation Day 2 (POD2), the result showed a significant difference in both groups with median values 2.50 in the control group compared to $97.0 \%$ (5.70) in the intervention group with $(Z=510.5, p=0.023)$.

Table 2 Comparison between control and intervention groups' median values of $\mathrm{SpO}_{2}$ scores

\begin{tabular}{|c|c|c|c|c|c|c|}
\hline \multirow[b]{2}{*}{ Group } & & \multirow[b]{2}{*}{$\mathrm{n}$} & \multicolumn{2}{|l|}{$\mathrm{SpO}_{2}$ score } & \multirow[b]{2}{*}{ Z } & \multirow[b]{2}{*}{$p$} \\
\hline & & & $\begin{array}{l}\text { Median } \\
\%\end{array}$ & $\begin{array}{l}\text { Mean } \\
\text { Rank }\end{array}$ & & \\
\hline Pre-intervention & Control & 38 & $99.0(6.00)$ & 43.75 & & \\
\hline (preoperative) & Intervention & 43 & $98.0(4.00)$ & 38.57 & 712.0 & 0.321 \\
\hline Post-intervention & Control & 38 & $98.0(5.00)$ & 36.02 & & \\
\hline (preoperative) & Intervention & 43 & $99.0(6.50)$ & 46.63 & 603.0 & $0.041^{*}$ \\
\hline Post-operative & Control & 38 & $96.0(3.00)$ & 35.60 & & \\
\hline day 1(POD1) & Intervention & 43 & $98.0(5.50)$ & 47.11 & 585.0 & $0.027^{*}$ \\
\hline Post-operative & Control & 20 & $96.0(2.50)$ & 38.10 & & \\
\hline (POD2) & Intervention & 18 & $97.0(5.70)$ & 48.19 & 510.0 & $0.023^{*}$ \\
\hline
\end{tabular}

\section{Comparison of Pao2 level between control and Intervention groups}

The level of $\mathrm{PaO} 2$ was assessed on pre-intervention (pre-operative), post-intervention (pre-operative), post-operative day 1(POD1) and post-operative day 2 (POD2). Mann-Whitney U-test was used to test the differences in $\mathrm{PaO} 2$ level scores between the control and intervention groups. $\mathrm{PaO} 2$ level was compared between control and intervention groups. The median ranks of $\mathrm{PaO} 2$ of the control and intervention groups are summarized in Table 4.3. The result shows no significant difference between both groups, with median value $120 \mathrm{mmHg}(7.00)$ in the control group and 4.00 in the intervention group with $(Z=93.5, p=0.293)$. In post-intervention there was no significant difference in both group with median value $152 \mathrm{mmHg}(7.50)$ in control group while 5.00 in intervention group with $(Z=81.1, p=0.121)$. On post-operation day 1(POD1), the result showed significant difference. In $\mathrm{PaO} 2$ score which is $89 \mathrm{mmHg}(3.00)$ in the control group compared to 6.50 in intervention group with $Z=53.5, p=0.008)$. On the POD 2, the median value of $\mathrm{Pa} 02$ scores from control and intervention groups were $95 \mathrm{mmHg}(4.00)$ and $83 \mathrm{mmHg}(1.00)$. The result showed no significant with $(Z=23.5, p=0.138)$ between two groups. In conclusion, the result shown no significant difference noted at the baseline data and post-intervention data on $\mathrm{PaO} 2$ score while there were significant differences found in the $\mathrm{PaO} 2$ scores between control and intervention group on the post-operation day 1(POD1).

Table 3 Comparison between control and intervention groups' median values of Pa02 scores

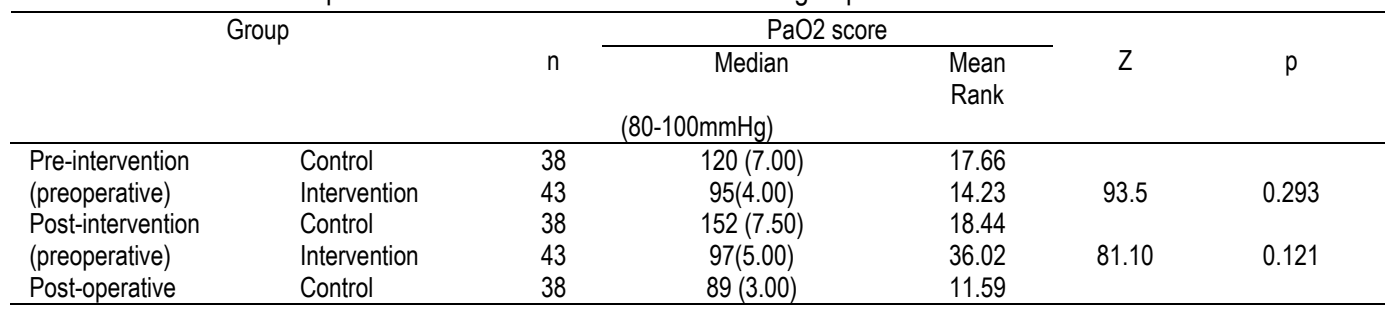




\begin{tabular}{|c|c|c|c|c|c|c|}
\hline \multirow{3}{*}{$\begin{array}{l}\text { Post-operative day2 } \\
\text { (POD2) }\end{array}$} & Intervention & 43 & $100(6.50)$ & 20.16 & 53.5 & $0.008^{*}$ \\
\hline & Control & 20 & $95(4.00)$ & 11.15 & & \\
\hline & Intervention & 18 & $83(1.00)$ & 7.44 & 23.5 & 0.138 \\
\hline
\end{tabular}

\section{Socio demographic data}

The control and intervention groups in this study were equal in terms of socio-demographic characteristics, including gender, age, ethnicity, level of education, occupation, prior hospitalization, and history of surgery. No significant difference $(p>0.05)$ were found when comparing the socio-demographic variable between the control and intervention groups. In addition, the participants from both control and intervention groups demonstrated the same socio-demographic characteristics. Therefore, none of socio-demographic characteristics was confounding variables that affected the results in this study.

\section{Oxygenation}

After the intervention of health education of deep breathing exercises, there was a significant decrease in the atelectatic area. The study also showed the deep breathing significantly increased the aerated total lung area, especially in the intervention group. This study also showed the immediate effect on SP02 after the performance on 30 deep breaths. In this study, a significant difference $(\mathrm{p}=0.041)$ was noted in the SpO2 post-intervention (pre-operative). Therefore, this study accepts the alternative hypothesis that there are differences between patients who received the routine pre-operative education and those who received the routine pre-operative education plus a structured pre-operative education intervention on $\mathrm{SpO}_{2}$ level post-intervention (pre-operative).

On POD 1, both groups showed reduction of $\mathrm{SpO}_{2}$ scores, but the intervention group showed a higher $\mathrm{SpO}_{2}$ score than the control group. There were significant differences in the $\mathrm{SpO}_{2}$ level between the two groups on POD $1(\mathrm{p}=0.027)$. Therefore the alternative hypothesis that there is a significant difference between patients who received the routine pre-operative education plus a structured preoperative education intervention on $\mathrm{SpO}_{2}$ level during POD1 was accepted. On POD2, the median values continue to increase from the previous assessment. There were significant differences in the $\mathrm{SpO}_{2}$ scores between the control and intervention groups on POD2 $(p=0.023)$. Therefore, the alternative hypothesis that there is a significant difference between patients who received the routine preoperative education plus a structured pre-operative education intervention on $\mathrm{SpO}_{2}$ level during POD2 was accepted.

\subsection{Discussion}

In these studies the result showed no significant difference on pre-intervention and post-intervention (pre-operative). However, after the health education of deep breathing exercises, the $\mathrm{PaO} 2$ score increased in the intervention group $(\mathrm{p}=0.008)$. Therefore, the alternative hypothesis was accepted with significant difference between patients who received the routine pre-operative education plus a structured pre-operative education intervention on SPO2 level during post-operative day (POD1).

To verify whether breathing exercises help to prevent pulmonary complications after heart surgery (Rodrigues et al., 2021) performed a meta-analysis using the following databases from Medline, Embase, CINAHL, and the Cochrane Library. Based on data from 11 trials (1240 patients), they concluded that pre-operative breathing intervention improves respiratory patient after surgery. Thus, respiratory physiotherapy for patients who underwent cardiac surgery may reduce post-operative pulmonary complications and their length of hospitalization. As mentioned above, the current range of techniques used in post-operative heart surgery is wide. However, there are controversies over the effectiveness of these procedures in reducing the incidence of respiratory complications and over the most appropriate strategy to identify which patients would benefit from such interventions (Fayyaz et al., 2016). Therefore, knowledge of the physiology and mechanisms that involve the post-operative pulmonary dysfunctions is necessary to define the therapy to be used (Miskovic \& Lumb, 2017). Therefore, a correct reading of these data provides a better approach to treating and caring for patients in the postoperative period after heart surgery.

In this study, the structured pre-operative education developed by researchers includes the definition of Deep Breathing Exercises (DBE) and steps to do deep breathing exercises. Pre-operative education intervention effectively post-operative oxygenation among other surgery such as orthopaedic surgery. According to Hussein and Taha, (2018), patients who practice deep breathing had a better quality of recovery in post-operative phase compared with those who do not practice. Therefore, the content of pre-operative education package should be informative and straightforward to ensure the effectiveness of the pre-operative education CABG surgery patient.

The finding of this study was consistent with the results of previous studies, which showed that pre-operative education has a positive effect on patients' oxygenation (Akinci et al. (2016); Chandrababu et al. (2017); Fayyaz et al. (2016); Zarneshan et al. (2021). The deep breathing exercises can easily be accomplished hourly and at a low cost. However, this technique will be better under supervision and assistance via deep breathing exercises instruction. PaO2 level was also assessed on pre-intervention, Post intervention (pre-operative), POD1 and POD 2. An inverse correlation between atelectatic area and arterial oxygenation ( $\mathrm{PaO} 2)$ is reported on the first and second post-operative days after open heart surgery. However, chronic obstructive pulmonary disease (COPD), general health status, smoking history and age are factors associated with increased risk for impaired lung volume after surgery Lacour, et al. (2018). 


\subsection{Conclusion and Recommendation}

In this study, the researchers designed a structured pre-operative education for patients undergoing CABG Surgery. The researcher developed a booklet titled "Breathing Exercises for Cardiac Surgery" to aid in the pre-operative education. The purpose of this pre-operative education is to hope that the patients can get a clear explanation regarding the surgery process and deep breathing exercises thus helping the patients prevent lung complications after an operation such as atelectasis. A standardized pre-operative structured education has not been implemented in this hospital and this present study has proved the effectiveness of the pre-operative education on level oxygenation especially in $\mathrm{PaO} 2$ and $\mathrm{SpO}_{2}$ which was supported by many previous studies. Therefore, the researchers strongly recommend implementing a structured pre-operative education in this tertiary hospital. The booklet implemented in this pre-operative education is an effective tool for helping post-CABG patients survive better and reduce the length of ventilated. Besides, a similar approach in this preoperative education could be adopted for the development of other education of other surgery or procedure. As a limitation of the study, an increased number of health education sessions may better understand participants about deep-breathing exercises.

Thefore, in future a more comprehensive pre-operative education intervention should be delivered by setting up a multidisciplinary preoperative team. The team should include surgeons, anaesthesiologist, physiotherapist, nutritionist, and nurses. Introducing the team to the patient on the day of admission and starting an educational package may help reduce respiratory complications. The surgeon's role is to explain the operation and pre-operative outcomes, whereas the anesthesiologists can cover anaesthesia information. Nurses may provide information related to pre-operative preparation, operating theatre environment and post-operative care. Besides that, nurses can focus on the learning needs of the patients and family members to formulate personalized information. Physiotherapists may provide early ambulation instructions to prevent muscle spasms and deep vein thrombosis. Nutritionists may explain post-operative fluids and diet. All these would help to improve communication between patients and different health personnel to enhance patient care. There will be no missed or double information delivered to patients in this way. The patients will also be familiar with the team involved in their care. Patient will perform the proper way of doing peep breathing exercises and functional activity post-operatively, early ambulation, wound care, postoperative nutrition after participating in the multidisciplinary pre-operative team.

\section{Acknowledgement}

We thank our colleagues from Universiti Teknologi MARA who provided insight and expertise that greatly assisted the research. Thank you to all participants, nurses, physiotherapist, dietician and medical attendant in Cardiothoracic Unit for their support and collaboration during data collection.

\section{Paper Contribution to Related Field of Study}

The result of this study perhaps could be used to enhance the pre-operative patient education practice among nurses and the multidisciplinary healthcare team.

\section{References}

Akıncı, B., Yeldan, I., Bayramoğlu, Z., \& Akpınar, T.B. (2016). The effects of posture and relaxation training on sleep, dyspnea, pain and, quality of life in the short-term after cardiac surgery: a pilot study. Turkish Journal of Thoracic and Cardiovascular Surgery, 24, 258-265.

Chandrababu, Ramesh \& Nayak, Baby \& Pai, Vasudev \& Patil, Nitin \& George, Anice \& George, Linu \& Devi, Elsa. (2017). Effect of Preoperative Education on Post-operative Outcomes Among Patients Undergoing Cardiac Surgery: A Systematic Review and Meta-Analysis. Journal of PeriAnesthesia Nursing. 32. 10.1016/j.jopan.2016.11.011.

Fayyaz, D. A., Furqan, D. A., Ammar, D. A., Altaf Ahmad, P. R., \& Ahmad, D. S. (2016). Pre-operative incentive spirometry; effectiveness to improve post-operative oxygenation in patients undergoing CABG surgery. The Professional Medical Journal, 23(11), 1368-1372. https://doi.org/10.17957/tpmi/16.3579

Franklin E, Anjum F. Incentive Spirometer and Inspiratory Muscle Training. (2021): StatPearls Publishing; 2021 Jan-. Available from: https://www.ncbi.nlm.nih.gov/books/NBK572114/

Hussein, Eman \& Taha, Nadia. (2018). Effect of Breathing Exercises on Quality of Recovery Among Post-operative Patients. International Journal of Studies in Nursing. 3. 151. 10.20849 /ijsn.v3i3.525

Lacour, M., Caviezel, C., Weder, W., \& Schneiter, D. (2018). Post-operative complications and management after lung volume reduction surgery. Journal of thoracic disease, 10(Suppl 23), S2775-S2779. https://doi.org/10.21037/jtd.2018.08.75

Liu, Y., \& Aungsuroch, Y. (2018). Factors influencing nurse-assessed quality nursing care: A cross-sectional study in hospitals. Journal of advanced nursing, 74(4), 935945. https://doi.org/10.1111/jan.13507

Malley, A., Kenner, C., Kim, T., \& Blakeney, B. (2015). The role of the nurse and the preoperative assessment in patient transitions. AORN journal, 102(2), 181.e1-181.e1819. https://doi.org/10.1016/j.aorn.2015.06.004

Miskovic A., \& Lumb A. B, (2017), Post-operative pulmonary complications BJA: British Journal of Anaesthesia, 118 (3), 317-334, https://doi.org/10.1093/bja/aex002

Rodrigues, S. N, Henriques, H. R., Henriques MA. (2021)Effectiveness of preoperative breathing exercises interventions in patients undergoing cardiac surgery: A systematic 
review. Rev Port Cardiol (Engl Ed).); 40(3):229-244. English, Portuguese. doi: 10.1016/j.repc.2020.08.013. Epub 2021 Mar 9. PMID: 33707091.

Ünver, S., Kivanç, G., \& Alptekin, H. M. (2018). Deep breathing exercises education receiving and performing status of patients undergoing abdominal surgery. International journal of health sciences, 12(4), 35-38.

Villa, G., Lanini, I., Amass, T. et al. (2020) Effects of psychological interventions on anxiety and pain in patients undergoing major elective abdominal surgery: a systematic review. Perioper Med 9, 38. https://doi.org/10.1186/s13741-020-00169-x

Zarneshan, A., Safaee, N., \& Esmelay, B. (2021). Effects of Combined Stretching and Breathing Exercises on Hemodynamic and Oxygenation Changes in Patients Undergoing CABG Surgery. Journal of Health and Care; 22(24), 327-338. 